\title{
EFFECT OF SELF-EFFICACY ON WORK ENGAGEMENT MEDIATED BY HRD CLIMATE ON OUTSOURCED BANK EMPLOYEES
}

\author{
Veranica Wijaya, Christine Winstinindah Sandroto \\ Atma Jaya Catholic University of Indonesia \\ Jln. Jenderal Sudirman Kav. 51, Jakarta 12930, Indonesia
}

\begin{abstract}
Human resources play a vital role in every company because human resources are the cogs for the running of the company. Nowadays, competition in any company is getting tougher, including the banking industry. This study aims to prove the effect of Self-efficacy on Work Engagement mediated by HRD Climate. This research was conducted at PT X as a third party, which is an outsourcing company for bank employees in Jakarta. Questionnaires were distributed to 150 employees, and data processing was done using SPSS v22 software and Hayes PROCESS v3 macros. The results of this study indicate that there is a positive and significant influence between the variable Self-efficacy on Work Engagement mediated by HRD Climate, with a more significant direct effect between the Self-efficacy variable on Work Engagement on outsourced bank employees in Jakarta.
\end{abstract}

Keywords: HRD climate, self-efficacy, work engagement

\section{INTRODUCTION}

Nowadays, the competition of companies in Indonesia is getting tougher, and so is the banking industry. Currently, the banking industry in Indonesia continues to proliferate, among others, with digitalization, interest rate competition, and competition for funds. Banks are institutions that get much attention from the community because they play an essential role and provide services to the community at large. Therefore, the role of human resource management in the banking world is the most important thing, because human resources are the cogs. It is not surprising that banks always make rigorous selections to obtain a

\footnotetext{
*Corresponding Author.

e-mail: christine.wins@atmajaya.ac.id
} 
supply of labor, as well as to develop existing employees. Rigorous selection is intended so that the company has qualified employees who are able to compete.

To get prospective employees who are qualified in the field according to their expertise is not easy. There are many forms of employment relationships that occur in companies, not just full-time. Some forms of employment are common, such as contract workers, apprentices, probation workers, casual daily laborers, and outsourced workers. Outsourcing is different from contract workers, where someone will be directly contracted by the company to work. Refer to Law No. 13 of 2003 concerning employment, and outsourcing is known as the provision of labor services as stipulated in articles 64, 65, and 66. In the world of Industrial Psychology, outsourcing employees are contract employees of a company providing outsourcing services. In other words, outsourcing companies are third-party companies that provide services and supply workers with specific criteria to companies that need them.

PT X, an outsourcing company supplying employees in several banks in Jakarta, stated that the self-efficacy of most employees is still lacking, causing low work engagement and unsatisfactory work results. Employees tend to work improperly and do not develop their abilities and potential. Self-efficacy is also related to the level of confidence of each individual and has an impact on productivity, stress levels, and mental health of employees. Based on these problems, the researchers examined the outsourcing of bank employees in Jakarta under PT X related to self-efficacy and work engagement of the company's employees along with HRD Climate.

\section{LITERATURE REVIEW}

\subsection{Self-efficacy}

According to Bandura (Feist \& Feist, 2010), self-efficacy is a person's belief in his ability to exercise some form of control over one's own functions and events in the environment. Self-efficacy, according to Suseno (2012), is a person's self-confidence in his abilities to organize and carry out a series of actions needed to produce something. Kreitner and Kinicki (2010) defined self-efficacy as a belief in one's own ability to deal with and solve problems effectively. Selfefficacy also means believing that one is able to succeed. They believe that having 
energy (motivation), resources (situational factors), understanding the right actions (role perception), and competence (ability) to do the task. Bandura, in Suseno (2012), argues that differences in the level of self-efficacy are influenced by several factors, namely: the nature of the task at hand, external incentives, one's status in the environment, and information about one's abilities.

\subsection{HRD-Climate}

HRD Climate is an integral part of organizational climate and is defined as "employee perceptions of the organizational development environment" (Rao and Abraham, 1986). HRD Climate is part of organizational climate that can include various characteristics such as the level of attention to human resources and the level of top management's confidence in the value and importance of training and human resource development. This builds effective communication systems in both directions, the spread of teamwork culture, and the rejection of cronyism, nepotism, and lack of justice and other behaviors that frustrate extraordinary human resources (Benjamin \& David, 2012; Chaudhary et al., 2012). According to Pareek (2012), Climate HRD is a process that helps individuals to acquire skills and abilities for their own development. Therefore, Climate HRD contributes to the development of current capabilities for employees and identification of their underlying abilities, acquisition of staff knowledge and skills that will enable them to do their current work and future work to be the best, and developing an organizational climate in general (Saraswathi, 2010). That is the perception employees can have about the organizational development environment concerning various HR practices and systems in the organization. (Purohit \& Verma, 2013)

HRD Climate is the perception employees have of policies, procedures, practices, and conditions that exist in the work environment. Climate HRD has characteristics including treating employees as an essential resource, understanding that developing employees is the work of every manager, believing in the ability of employees, communicating openly, and encouraging to take risks and experiment. HRD Climate has three dimensions (Rao and Abraham, 1986), namely: General Climate, HRD Mechanism, and OCTAPAC Culture (Openness, Confrontation, Trust, Autonomy, Pro-Activity, Authenticity, and Collaboration). 


\subsection{Work Engagement}

Work engagement is a condition where members of an organization identify themselves with work, in a state of attachment a person will employ him and express himself physically, cognitively, and emotionally during work (Kahn, 1990). Maslach, Jackson, \& Leiter (Cole et al., 2011) also suggested the definition of work engagement, namely the spirit of work in the form of dedication to work performance and work effectiveness shown by employees. Schaufeli \& Bakker (2004) defines work engagement as a satisfied and happy mental condition related to work, characterized by enthusiasm, dedication, and appreciation. Schaufeli \& Bakker (2003), on the other hand, stated that work engagement has the opposite understanding of burnout.

Employees who experience work engagement have a sense of enthusiasm and have a productive relationship with their work activities. They see themselves as people who can deal well with their work demands Schaufeli, Salanova, Gonzales-Roma, \& Bakker (2001) explain the dimensions that are contained in work engagement, namely: vigor, dedication, and absorption.

Federman (2009) suggests that workers who have high work engagement are characterized as follows: focusing on completing a job and also on the next job, feeling as part of a team and something greater than themselves, able and without pressure in making leaps at work, and working with change and approaching challenges with a mature behavior. The factors driving work engagement according to Perrin (2003) include senior management that pays attention to the existence of workers, jobs that provide challenges, decisionmaking authority, companies or organizations that focus on customer satisfaction, have wide-open opportunities for a career, company reputation, reliable work teams and mutually supportive ownership of the resources needed to be able to show excellent work performance, have the opportunity to give an opinion when making decisions, and deliver a clear vision of the organization by senior management about the organization's long-term targets.

\subsection{Previous Studies}

Previous research has been carried out by Richa Chaudary, Santosh Rangnekar, and Mukesh Kumar Barua, which was conducted on 150 workers, both managers and non-managers in several companies in India. The research was published, and 
the article was titled "Relationship between occupational self-efficacy, human resources climate development, and work engagement" (2012). The article presents four hypotheses; namely, Occupational Self-efficacy has a positive relationship with Work Engagement, HRD Climate has a positive relationship with Work Engagement, Self-efficacy has a positive relationship with HRD Climate, and finally, HRD Climate will mediate the relationship between Self-efficacy and Work Engagement.

Researchers also use supporting journals in this study was conducted by Ewis (2015) with the title "The role of HRD Climate in building positive job attitudes and extra-role behaviors." This research was conducted in Saudi Arabia, with 246 employees from 3 Saudi Telkom companies. And it was found that HRD Climate significantly and positively influenced organizational behavior, work engagement, and organizational citizenship behavior.

\section{Research Model}

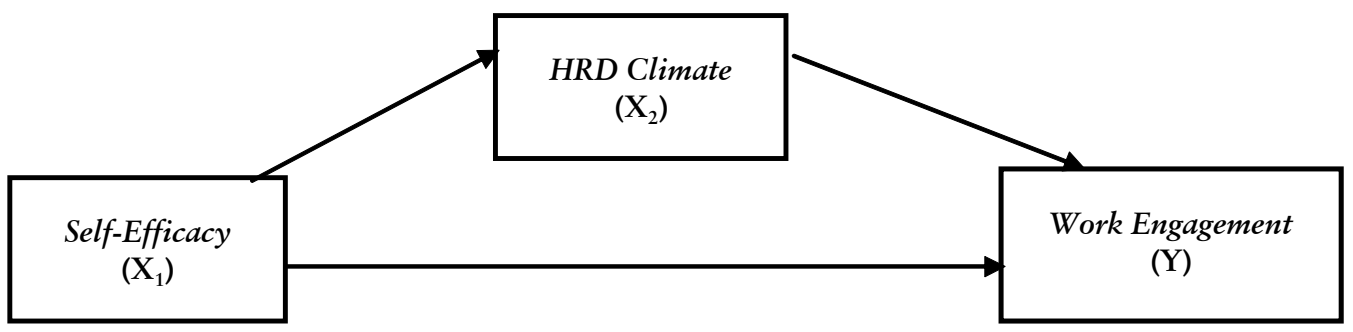

Based on the research model above, the hypotheses used in this study are:

Hypothesis 1: Self-efficacy has an influence on HRD Climate on bank outsourcing employees

Hypothesis 2: HRD Climate has an influence on Work Engagement in bank outsourcing employees

Hypothesis 3: Self-efficacy has an influence on Work Engagement on bank outsourcing employees

Hypothesis 4: HRD Climate mediates the effect of Self-efficacy on Work Engagement on bank outsourcing employees.

\section{RESEARCH METHODS}

\section{Population and Research Sample}

The population that will be used in this study are employees of outsourcing banks in Jakarta under PT X, totalling at 480 people. Some banking clients that 
use the services of PT X are ANZ Bank, CTBC Bank, DBS, UOB, QNB Indonesia Bank, Commonwealth Bank, PT Bank Maybank Indonesia Tbk, BNI, Mandiri Bank, BNI Syariah, and Bank Danamon Indonesia. The sample in this study amounted to 150 respondents. According to Roscoe in Sekaran \& Bougie (2016), the minimum acceptable sample for correlational research amounts to no less than 30. Also, the data collection technique is convenience sampling. Convenience sampling is a technique for determining research samples by attracting members of the population based on the ease of being found or the availability of individual population members only (Istijanto, 2008).

To measure all indicators used, the authors use a Likert scale, scale 1-6, scale 1: strongly disagree to scale six strongly agree. Self-Efficacy Questionnaire, adapted from Occupational Self-efficacy prepared by Pethe et al. (1999). Examples of items asked include: When faced with a difficult task, one is willing to do anything to achieve it, and one realizes his strengths, and one continues to develop it. To measure Work Engagement, the author uses UWES (Utrecht Work Engagement Scale) made by Schaufeli et al. (2002). Examples of items asked are: At work, I feel full of energy, I am proud of the work I do, and time passes quickly when I work. To measure HRD Climate, the authors use the HRD Climate Instrument Survey made by Rao and Abraham (1986). Examples of items in question are: the top management of this organization is trying hard to ensure that employees enjoy their work, employees are sponsored for training programs based on training needs, and employees are encouraged to take the initiative and do it yourself without having to wait for instructions from supervisors.

\subsection{Results}

\section{Reliability and Validity Tests}

The reliability test analysis in the study was conducted by looking at the Cronbach's Alpha coefficient. If the Cronbach Alpha coefficient $\geqslant 0.7$, it can be said that the variable is reliable (Johnson \& Christensen, 2012). The Cronbach Alpha for each variable is as follows: self-efficacy: 0.899; work engagement: 0.891; and Climate HRD: 0.964. Thus, the three research variables are reliable. 
Testing the validity in this study, researchers used a technique to compare the value of R-count (Corrected Item-Total Correlation) with r-table. The r-table value is obtained from the distribution table with a level of $\alpha=0.05$ and $\mathrm{df}$ (degree of freedom) of $148(\mathrm{~N}-2)$. Then the r-table obtained $=0.1603$. The statements in the questionnaire are valid if the value of Corrected Item-Total Correlation is greater than 0.1603. Corrected item-total correlation for each variable is in the range as follows: self-efficacy: 0.548-0.694; work engagement: 0.525-0.686; and Climate HRD: 0.51-0.795.

\section{Descriptive Statistics}

Table 1- Characteristics of respondents

\begin{tabular}{lll}
\hline & Frequency & Percentage \\
\hline Gender & & \\
Male & 83 & 55.3 \\
Female & 67 & 44.7 \\
Total & 100 & 100 \\
& & \\
Age & & \\
$20-30$ & 90 & 60 \\
$>30-40$ & 46 & 30.7 \\
$>40$ & 14 & 9.3 \\
Total & 150 & 100 \\
& & \\
Education & & \\
Undergraduate degree & 128 & 85.3 \\
Postgraduate degree & 22 & 14.7 \\
Total & 150 & 100 \\
\hline
\end{tabular}

Based on Table 1 it can be seen that the majority of respondents are male $(55.3 \%)$, with an age range of $20-30$ years $(60 \%)$ and undergraduate degree education level (85.3\%).

\section{Hypothesis Testing}

This study uses a regression test with mediator variables. Baron and Kenny (1986) called a variable as mediator if the variable also influences the relationship between the predictor variable (independent) and the criterion (dependent). 
Review of Management and Entrepreneurship

Volume 04, Number 02, October 2020

\section{Hayes Macro Test Results}

Run MATRIX procedure:

$* * * * * * * * * * * * *$ PROCESS Procedure for SPSS Release $2.16 .1 * * * * * * * * * * * * * * * * * * *$

Written by Andrew F. Hayes, Ph.D. www.afhayes.com

Documentation available in Hayes (2013). www.guilford.com/p/hayes3

$$
\begin{gathered}
\text { Model }=4 \\
\mathrm{Y}=\mathrm{WE} \\
\mathrm{X}=\mathrm{SE} \\
\mathrm{M}=\mathrm{HRDC}
\end{gathered}
$$

Sample size

150

Outcome: HRDC

Model Summary

$$
\begin{array}{cccccccr}
\text { R } & \text { R-sq } & \text { MSE } & \text { F } & \text { df1 } & \text { df2 } & p & \\
.6780 & .4597 & 204.1653 & 125.9382 & 1.0000 & 148.0000 & .0000
\end{array}
$$

Model

$$
\text { coeff se } t \quad p \quad \text { LLCI ULCI }
$$

$\begin{array}{lllllll}\text { constant } & 40.3783 & 9.1385 & 4.4185 & .0000 & 22.3195 & 58.4371\end{array}$

$\begin{array}{lllllll}\mathrm{SE} & 2.1141 & .1884 & 11.2222 & .0000 & 1.7418 & 2.4863\end{array}$

$* * * * * * * * * * * * * * * * * * * * * * * * * * * * * * * * * * * * * * * * * * * * * * * * * * * * * * * * * * * * * * * * * * * * * * * * * *$

Outcome: WE

Model Summary

$\begin{array}{cccccrcr}\mathrm{R} & \mathrm{R}-\mathrm{sq} & \mathrm{MSE} & \mathrm{F} & \mathrm{df} 1 & \mathrm{df} 2 & \mathrm{p} & \\ .8356 & .6982 & 13.5475 & 170.0340 & 2.0000 & 147.0000 & .0000\end{array}$

Model

$\begin{array}{lcrrcccc} & \text { coeff } & \mathrm{se} & \mathrm{t} & \mathrm{p} & \text { LLCI } & \text { ULCI } & \\ \text { constant } & 1.7909 & 2.5045 & .7151 & .4757 & -3.1586 & 6.7403 \\ \text { HRDC } & .1380 & .0212 & 6.5166 & .0000 & .0961 & .1798 \\ \text { SE } & .5454 & .0660 & 8.2616 & .0000 & .4150 & .6759\end{array}$

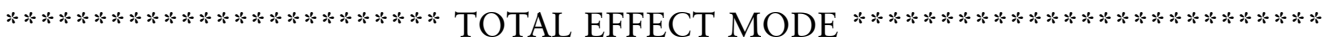

Outcome: WE 
Veranica Wijaya, Christine Winstinindah Sandroto / Effect of Self-Efficacy on Work Engagement Mediated by Hrd Climate on Outsourced Bank Employees

Model Summary

$\begin{array}{cccccrcr}\mathrm{R} & \mathrm{R}-\mathrm{sq} & \mathrm{MSE} & \mathrm{F} & \mathrm{df} 1 & \mathrm{df} 2 & \mathrm{p} & \\ .7817 & .6110 & 17.3432 & 232.4687 & 1.0000 & 148.0000 & .0000\end{array}$

Model

\begin{tabular}{|c|c|c|c|c|c|}
\hline & $\cos$ & eff & e & LLCI & ULCI \\
\hline constant & 7.3625 & 2.6635 & 2.7642 & 2.0991 & 12.6258 \\
\hline SE & .8371 & .0549 & 15.2469 & .0000 & .9456 \\
\hline
\end{tabular}

Total effect of X on Y

$\begin{array}{cccccc}\text { Effect } & \text { SE } & \mathrm{t} & \mathrm{p} & \text { LLCI } & \text { ULCI } \\ .8371 & .0549 & 15.2469 & .0000 & .7286 & .9456\end{array}$

Direct effect of $\mathrm{X}$ on $\mathrm{Y}$

$\begin{array}{cccccc}\text { Effect } & \text { SE } & \mathrm{t} & \mathrm{p} & \text { LLCI } & \text { ULCI } \\ .5454 & .0660 & 8.2616 & .0000 & .4150 & .6759\end{array}$

Indirect effect of $\mathrm{X}$ on $\mathrm{Y}$

Effect Boot SE BootLLCI BootULCI

$\begin{array}{lllll}\text { HRDC } & .2917 \quad .0728 \quad .1561 & .4354\end{array}$

Partially standardized indirect effect of X on $\mathrm{Y}$

Effect Boot SE BootLLCI BootULCI

$\begin{array}{lllll}\text { HRDC } & .0438 & .0113 & .0229 & .0663\end{array}$

Completely standardized indirect effect of X on Y

Effect Boot SE BootLLCI BootULCI

$\begin{array}{lllll}\text { HRDC } & .2724 & .0660 & .1478 & .4034\end{array}$

Ratio of indirect to total effect of $\mathrm{X}$ on $\mathrm{Y}$

Effect Boot SE BootLLCI BootULCI

$\begin{array}{lllll}\text { HRDC } & .3485 & .0951 & .1798 & .5469\end{array}$

Ratio of indirect to direct effect of X on $\mathrm{Y}$

Effect Boot SE BootLLCI BootULCI

$\begin{array}{lllll}\text { HRDC } & .5348 & .2660 & .2192 & 1.2072\end{array}$

R-squared mediation effect size (R-sq_med)

Effect Boot SE BootLLCI BootULCI

$\begin{array}{lllll}\text { HRDC } & .4709 & .0540 & .3635 & .5734\end{array}$ 
Number of bootstrap samples for bias corrected bootstrap confidence intervals: 5000

Level of confidence for all confidence intervals in output:

95.00

NOTE: Kappa-squared is disabled from output as of version 2.16. END MATRIX

Hayes Test Results

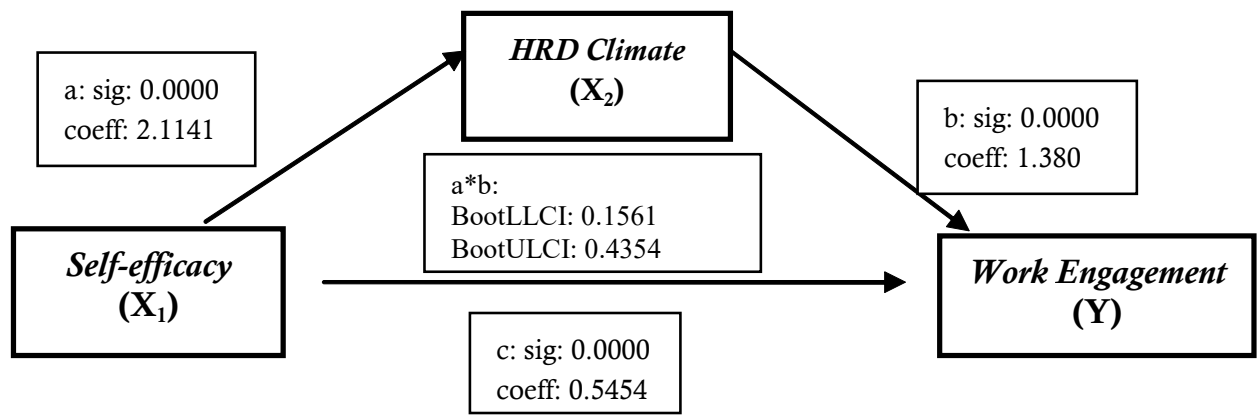

Based on the results of the Hayes test above, the independent variable is Self-efficacy (SE) with an expected mediating variable HRD Climate (HRDC). The results above shows that $\mathrm{P}=0.0000<\alpha=0.05$, with a coefficient value of 2.1141, meaning that there is a significant effect of Self-efficacy on HRD Climate, thus hypothesis 1 is accepted. Hayes's test results also showed an association between HRD Climate expected mediation variables and the Work Engagement (WE) dependent variable. The calculation results show $\mathrm{P}=0.0000$ $<\alpha=0.05$, with a coefficient value of 0.1380 , meaning that there is a significant influence for HRD Climate on Work Engagement, thus hypothesis 2 is accepted. The direct effect between the independent variable Self-efficacy (SE) on the dependent variable Work Engagement (WE). From the results of the calculation above, the output SPSS shows $\mathrm{P}=0.0000<\alpha=0.05$, with a coefficient value of 0.5454 , meaning that there is a significant direct effect between Self-efficacy on Work Engagement, thus hypothesis 3 is accepted. Hayes test results also 
showed an indirect effect between the independent variable Self-efficacy (SE) on the dependent variable Work Engagement (WE). The indirect effect is the value of the effect that is produced indirectly in the relationship of the independent variable to the dependent variable mediated by the expected mediating variable. From the calculation results above, the SPSS output shows $\mathrm{P}=0.0000<\alpha=$ 0.05, with coefficient value 0.2917, and shows BootLLCI: 0.1561 and BootULCI: 0.4354 , it can be concluded that there is an indirect effect of Self-efficacy on Work Engagement through HRD Climate, thus hypothesis 4 is accepted. Direct effect coefficient: 0.5454 while indirect effect: 0.2917 , the effect of direct effect is more significant than the indirect effect.

The summary of the model in the SPSS output shows the amount of R2 and F value. R2 value of 0.6982 or $69.82 \%$, which means $69.82 \%$ of the Work Engagement variable can be explained by the Self-efficacy and HRD Climate variables, while $30.18 \%$ is influenced by other factors not examined in this study.

\section{DISCUSSION}

The results showed that Self-efficacy had a positive influence on Work Engagement and HRD Climate. This study adopts previous research conducted by Chaudhary, Rangnekar, and Barua (2012), which shows that Self-efficacy has a positive influence on HRD Climate. However, in this study, the authors use bank outsourcing employees as objects. From the results of the study, the authors found similarities with previous studies. The Self-efficacy variable has a positive effect on HRD Climate, which means that if the Self-efficacy owned by an outsourcing bank employee is high then the individual will believe in his competence and ability which will make the individual's mood to be good or positive to provide a positive work atmosphere (including dealing with rules, company policies at the bank where they work), and vice versa.

Secondly, there are also the results of the analysis of this research model in accordance with a research by Ewis (2015) which shows that HRD Climate has a positive influence on Work Engagement. From the results of research by the author, there is a similarity that the HRD Climate variable has a positive influence on Work Engagement, which means a positive and comfortable work atmosphere makes individuals have a high working engagement with the com- 
pany, even when placed in any bank. Individuals will complete their work assignments with a good mood, feeling comfortable, and will be able to complete their work beyond their intended target.

Next is the result of Wahyuni's research (2017), which shows that SelfEfficacy has a positive influence on Work Engagement. In the research conducted by the author, the Self-Efficacy variable has a positive influence on Work Engagement, which means that if an individual has high confidence that he is able to do the work given, then the individual will have a strong sense of being attached to his work and have a sense enthusiastic about work, employees will also concentrate fully and seriously when working.

The author also found that the HRD Climate variable as a mediating variable of Self-Efficacy on Work Engagement has a positive effect. This means that with a work environment that supports employees to work and is positive such as two-way communication, training that supports the development of employee potential, rewards given for achieving specific targets, the occurrence of healthy competition and the absence of discrimination will make employees feel comfortable to work and can improve individual self-efficacy. Furthermore, when the self-efficacy of the individual increases, it will also affect employees' work engagement with their work, and individuals feel more valued. They will carry out their work happily, not with a feeling of being burdened. Self-Efficacy will affect one's work productivity. Low Self-efficacy makes a person feel the pressure or demands of work to be high and have an impact on employee mental health (easy stress). A Work Engagement can prevent stress levels and individual anxiety levels, this is because individuals know they are able to complete any task as complicated as, and they can communicate with their supervisors or colleagues without fear. Individuals will also feel satisfied with their work. The components contained in Climate HRD, namely effective communication in both directions, the spread of teamwork culture, and treating all employees somewhat can be supporting things to make the work atmosphere comfortable and positive which will affect the mood of employees who will also be supporting things for SelfEfficacy.

Author's suggestion is that PT. X pays attention and manages well every potential possessed by individuals as prospective employees who will be placed in a bank in Jakarta so that each individual has high self-efficacy, namely a sense 
of confidence and confidence regarding his ability to do a job so that it has satisfying results for himself and the organization where the individual works.

\section{CONCLUSION}

Based on the results of the study it can be concluded that there is a significant effect of Self-Efficacy on HRD Climate, there is a significant effect of HRD Climate on Work Engagement, there is a significant influence between SelfEfficacy on Work Engagement, and there is a significant effect of Self-Efficacy on Work Engagement mediated by HRD Climate to bank employees in Jakarta under PT. X.

\section{REFERENCES}

Baron, R.M. \& Kenny, D.A. The Moderator-Mediator Variable Distinction in Social Psychological Research: Conceptual, Strategic, and Statistical Considerations. Journal of personality and Social Psychology, 51 (6), 11731182.

Benjamin, A., \& David, I. 2012. Human Resource Development Climate and Employee Commitment in Recapitalized Nigerian Banks. International Journal of Business and Management, 7(5), 91-99. http://search.proquest. com/docview/1014404466? accountid=142908.

Chaudhary, Richa., Ragnekar, Santosh., and Barua, Mukesh Kumar. (2012), Relationship between occupational self-efficacy, human resource development climate, and work engagement, Journal of Team Performance Management, 18 (7/8).

Chaudhary, Richa., Ragnekar, Santosh., and Barua, Mukesh Kumar. (2013),, Engaged versus Disengaged: The Role of Occupational Self-efficacy, Asian Academy of Management Journal, 18 (1), 91-108.

Ewis, Mamdouh Zaky. 2015. The Role of Human Resources Development Climate in Building Positive Job Attitudes and Extra-Role Behaviors, International Journal of Business and Management; 10 (5). 
Federman, Brad. 2009. Employee Engagement: A Roadmap for Creating Profits, Optimizing Performance, and Increasing Loyality. San Francisco: JosseyBass A Wiley Imprint.

Feist, J., \& Feist, Gregory, J. 2010. Teori Kepribadian, Theories of Personality, Buku 2, Edisi 7. Jakarta: Salemba Humanika.

Kahn, W.A. 1990. Psychological Condition of Personal Engagement and Disengagement at Work. Academy of Management Journal, 33, 692-724.

Kreitner, Kinicki. 2010. Organizational Behavior. New York: McGraw-Hill.

Perrin, T. 2003. Working today: Understanding what drives employee engagement the 2003. Towers Perrin Talent Report. US Report.

Purohit, B., \& Verma, R.K. 2013. A Study of Human Resources Development Climate in Goverment Health Centres in India. Journal of Health Management, 15(3), 431-443. http://dx.doi.org/10.1177/0972063413491878.

Rao, T.V. and Abraham, E. 1986. "HRD Climate in Organizations", in Rao, T.V. (Ed), Readings in Human Resources Development, IBH Publishing, Oxford and New Delhi, pp.36-45.

Schaufeli, Wilmar \& Bakker, Arnold. 2004. Utrecht Work Engagement Scale, Preliminary Manual, Version 1.1.

Schaufeli, W.B., Salanova, M.M., Gonzales-Roman, V., \& Bakker, A.B. 2002. The Measurement of Engagement and Burnout: A Two Sample Confirmatory Factor Analytic Approach. Journal of Happiness Studies, 3, 71-92.

Sekaran, Uma \& Bougie, Roger. 2016. Research Methods for Business: a Skill Building Approach. John Wiley \& Sons. 